\title{
Microstructural Characterization of Co-Cr-Mo-W Alloy as Casting for Odontological Application
}

\author{
Priscila S. N. Mendes ${ }^{1}$, Jefferson Fabrício C. Lins ${ }^{1}$, Patrícia S. N. Mendes ${ }^{1}$, \\ Willie R. Prudente ${ }^{1}$, Rodrigo P.Siqueira ${ }^{1}$, Rodrigo E. Pereira ${ }^{1}$, Said M.S. \\ Rocha $^{2}$, Alexandre R. Leoni ${ }^{2}$ \\ ${ }^{1}$ Departamento de Engenharia Metalúrgica, Universidade Federal Fluminense, Volta Redonda, RJ, Brazil. \\ ${ }^{2}$ Departamento de Engenharia Mecânica, Universidade Federal Fluminense, Volta Redonda, RJ, Brazil.
}

\begin{abstract}
Interest in the analysis and material characterization is rising due to the necessity of the adequate material selection based on system performance in study. The analysis and knowledge of the microstructure and the mechanical properties of any material are of utmost importance since it aims primarily to estimate the performance during the material life span, minimizing the possibility of degradation and undesirable flaws during product utilization. Co-Cr-Mo-W alloys have been well accepted in odontology as prosthesis material, due to its high mechanical resistance, good corrosion resistance and exceptional biocompatibility properties. This study aims to characterize the microstructure of a cobalt based alloy (Co-Cr-Mo-W) obtained through vacuum casting process. Optical microscopy, electronic sweeping microscopy and X-ray were employed and Vickers hardness test with loads of $100 \mathrm{gf}, 500 \mathrm{gf}$ and 1000 gf during $10 \mathrm{~s}$. Microstructure casting is characterized by a Co-fcc dendritic matrix with a secondary phase, as well as $\mathrm{M}_{23} \mathrm{C}_{6}$ precipitate carbides in the interdendritics zones and grain boundaries. The precipitation of carbides represents the main device of strengthening in the cast state for these types of alloys and is also responsible for its lower mechanical properties. The material attained hardness between 25 and 35 HRC, meeting the ASTM F75 standards.
\end{abstract}

Keywords: carbide, characterization, Co-Cr-Mo-W alloys, dental alloys, microstructure.

\section{INTRODUCTION}

The dental implants already correspond to $18 \%$ of the global market of dental devices and, furthermore, it has one of the higher growth rates. The implant market has reached US\$ 3.2 billion in 2010 and approximately US $\$ 4.2$ billion in 2015 [1].

Since the beginning of the century, many studies have been made in order to develop for dental usage, alternative alloys which could safely replace the gold based alloys.

By analyzing various basic metal alloys for dental restorations, it has been noted that, among the basic metal alloys, those composed basically of $70 \%$ of $\mathrm{Co}$ and $30 \%$ of $\mathrm{Cr}$ provided satisfying values of mechanical resistance, hardness and abrasion resistance. It was verified that other elements like $\mathrm{Mo}, \mathrm{W}$ and $\mathrm{C}$ also belong to these alloys, the latter being the biggest responsible for the improvement of mechanical properties. Co is the main responsible for the modulus of elasticity, $\mathrm{Cr}$ grants the corrosion resistance forming a passive oxide layer and Mo contributes to the growth in mechanical resistance.

Some advantages of basic metal alloys, such as lighter weight, lower costs, high stretch modulus and easier casting, provided the acceptance of these materials. Cobalt based alloys form a class of high corrosion resistant materials in physiological environments and high wear resistance, overcoming the stainless steel alloys. Furthermore, the elevated fatigue resistance and the high resistance limit allow its application wherever there's a requirement for a long-life span with no occurrence of fatigue, stress or fracture. Those characteristics have led to the utilization of these alloys in many biomedical applications [2] [3].

The improvement of performance in the last 40 years have been achieved with composition alteration, insertion of new alloy elements $(\mathrm{Si}, \mathrm{Nb}$, $\mathrm{Ir}, \mathrm{W}$, for example) in low concentrations, heat treatments and the evolution of technological processes of acquisition and casting of these materials [4].

Due to the high variety of casting alloys of widely diverse compositions and broadly applications, it's hard to idealize a flexible classification system to accommodate new formulations or alterations of the existing systems without a constant literary revision.

\section{EXPERIMENTAL PROCEDURE}

\subsection{Materials}

The material utilized in this study is a Co metal based alloy, in addition to $\mathrm{Cr}$, Mo and W. It was produced by vacuum casting in cylindrical ingot shape with $100 \mathrm{~mm}$ of diameter, as shown in Figure 1 


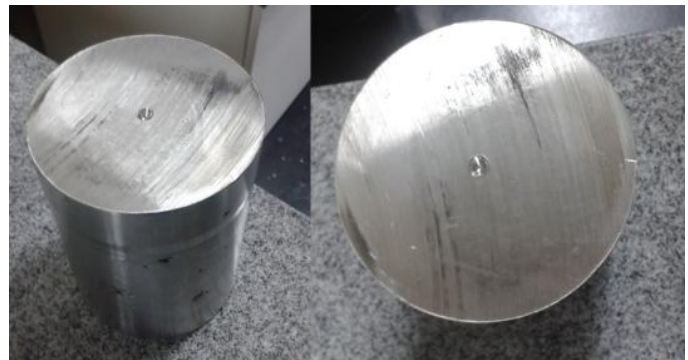

Figure 1: Cylindrical ingot of Co-Cr-Mo-W alloy provided for study.

The alloy chemical composition is shown in Table 1 . Table 1: Chemical composition of the alloy under study (in wt. \%)

\begin{tabular}{|c|c|c|c|c|}
\hline Element & Co & Cr & Mo & W \\
\hline (\% wt.) & 65,00 & 21,9 & 6,00 & 6,00 \\
\hline
\end{tabular}

\subsection{Methods}

\subsubsection{Metallographic preparation}

The Co-Cr-Mo-W samples were polished with the Arotec Aropol 2V equipment, with a tandem of sandpapers with silicon carbide basis of 600\#, 800\#, 1000\#, 1200\# and 2500\#. For the sample polishing, a diamond paste with 3 and $1 \mu \mathrm{m}$ granulation were adopted, until a self-acquired sample for image acquisition in a electronic microscope were obtained.

To reveal the microstructure of the $\mathrm{Co}-\mathrm{Cr}$ Mo-W alloy, a chemical etching with a $5 \% \mathrm{HCl}$ and $95 \%$ water solution with the support of a ElectroMet ${ }^{\circledR}$ of 4 and $5 \mathrm{~V}$ equipment was realized during 40s [5].

\subsubsection{Optical microscopy (OM)}

Optical microscopy allows the obtainment of topography images and microstructural or macrostructural characterization of polished and etched surfaces with increases of 50 to 1000 times. It also makes the analysis of grain size, phase distribution, inclusion and mechanical strains easier.

In this study, a first analysis of the surface for microstructural verification was performed using the NIKON LV150 microscope and the "Stream Basic 8.1" image capturing software.

\subsubsection{Scanning electron microscopy (SEM)}

In this technique a ray of electrons with controlled diameter is projected over the surface of the sample, the signals provided by the collisions of these electrons with the electrons at the surface are acquired by the microscope.

The microstructure of the samples were observed with the aid of a Zeiss EVO MA10 scanning electron microscopy with LaB6 filament.

\subsubsection{X-ray diffraction (DRX)}

This technique allows the identification of the lattice structure, crystallographic texture and the relation between the phase orientation.

The X-ray diffraction analysis (DRX) was performed by a Lab X XRD-600 Shimadzu diffractometer, using $\mathrm{Cu}-\mathrm{K} \alpha$ radiation, with standard goniometer. It was applied $30 \mathrm{kV}$ of tension, $30 \mathrm{~mA}$ of current during a sweeping between 10 and $85^{\circ}$ of $2 \theta$, with a step of $2 \theta$ equal to $0,02^{\circ}$ and sweeping speed of $2^{\circ}$ per minute. The peaks have been identified through comparison with microfilms of the JCPDS archive and Powder Cell software.

\subsubsection{Micro hardness Vickers (HV)}

Studying the mechanical properties is necessary to know the properties and to predict material behavior in the oral cavity. For the test a HMV-2T model Shimadzu micro durometer was employed. Vickers impressions were realized with loads of $100 \mathrm{gf}, 500 \mathrm{gf}$ and $1000 \mathrm{gf}$ during $10 \mathrm{~s}$.

\section{RESULTS AND DISCUSSION}

\subsection{Microstructural characterization}

The alloy microstructure is defined during the cooling and solidification processes. In this process occurs the second phase precipitation resulting from the matrix saturation, which splits the bonding elements forming, for example, carbides of $\mathrm{M}_{7} \mathrm{C}_{3}$ and $\mathrm{M}_{23} \mathrm{C}_{6}$ types ( $\mathrm{M}=\mathrm{Co}, \mathrm{Cr}$ or $\mathrm{Mo}$ ) [6] [7].

Microstructures of dental alloys with similar compositions present a dominant phase dendritic face-centered cube (FCC) rich in cobalt, and one or more phases of interdendritics carbides (chromium and molybdenum) [8]. Literary data also reveal the existence of an $\alpha$ phase as a matrix composed specially of cobalt and interdendritics regions rich in molybdenum.

The microstructure of the Co-Cr-Mo-W alloy observed by optical microscopy was formed by a dendritic Co-FCC matrix with the presence of precipitates on grain boundaries and interdendritics zones, which agreed well with those descripted in literature for these alloy types in the as-cast condition. It was also detected the presence of casting flaws such as micropores, probably due to the elevated leakage temperature.

The formation of the dendritic structure happens in parallel to the solid/liquid interface and in the direction of the heat extraction. Therefore, if the solute concentration in the alloy is constant, the higher is the solidification rate, the lower is the dendritic spacing and, if the solidification rate is constant, the dendritic spacing will be influenced by the solute concentration in the alloy. These factors can be the cause of different structures found in the Co-Cr-Mo-W alloys [8] [9]. Pure cobalt at ambient temperature has an hexagonal close-packed (HCP) 
structure and shows an allotropic transformation to face-centered cubic (FCC) structure at $400^{\circ} \mathrm{C}$. The addition of alloy elements such as chromium $(\mathrm{Cr})$ and tungsten (W) increases this transformation temperature. Co based alloys display a metastable dendritic matrix $\alpha$-FCC due to the slow nature of the FCC $\rightarrow$ HCP transformation [6], and a precipitate formed mainly by $\mathrm{M}_{23} \mathrm{C}_{6}$ carbides.

Figure 2 and Figure 3 shows an as-cast alloy microstructure in detail.

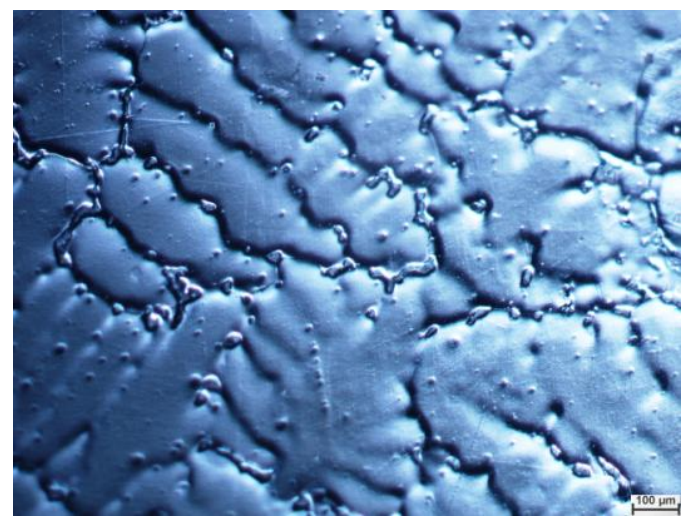

Figure 2: Optical micrograph of the as-cast microstructure.

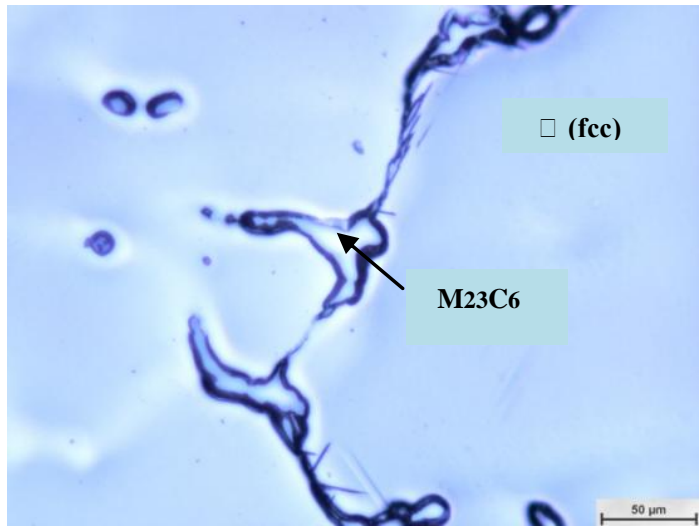

Figure 3: Identification of different phases present.

The carbide precipitation represents the main device of strengthening in the cast state for these alloy types and is also responsible for lower mechanical properties. The type, size and volume fraction of the carbide depends upon the solidification conditions, as well as the chemical composition. The forming elements of carbide, together with the amount of carbon in the alloy fulfill a considerable role in the composition and morphology of the precipitated carbides [10].

Figure 4 and Figure 5 show the morphology of the main phases present in the $\mathrm{Co}-\mathrm{Cr}-\mathrm{Mo}-\mathrm{W}$ ascast alloy in a SEM micrograph of secondary electrons.

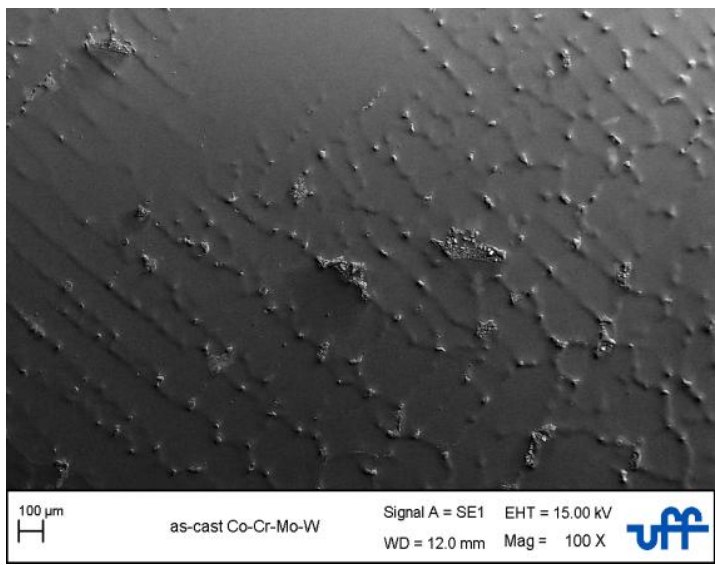

Figure 4: Main phases present, shown in an electron micrograph (SE-SEM).

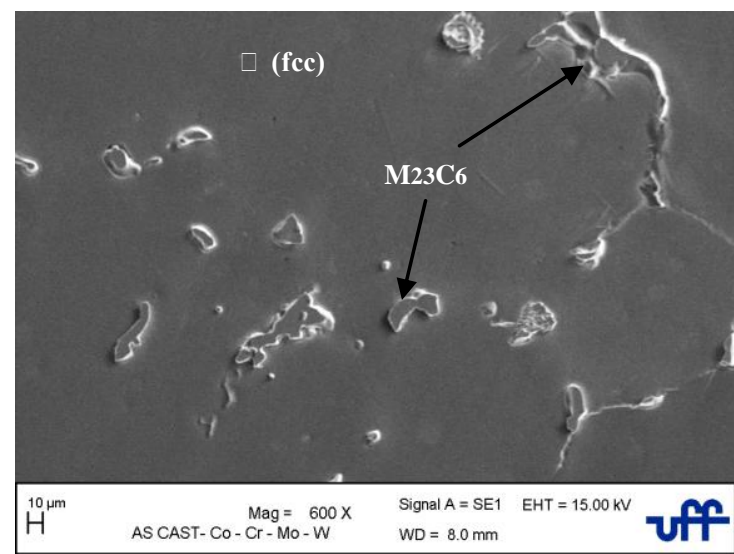

Figure 5: Main phases present in alloy, shown in an electron micrograph (SE-SEM). Analysis of the M23C6 carbide phase analysis of the $\mathrm{Co}-\mathrm{Cr}-\mathrm{Mo}-\mathrm{W}$ rich uniform matrix.

\subsection{X-ray diffraction (DRX)}

Figure 6 shows the X-ray diffraction results realized in the metal alloy developed in this study. It can be observed that only peaks of diffraction from the metal cobalt have been detected, indicating that the components form a solid solution with this metal. Based on the chemical analysis presented in Table 1, the cobalt (Co) is found in higher concentration around $65 \%$ in weight. Considering the phases diagrams and characteristics of each metal present in the global composition of the alloy, the metals are expected to have an atomic structure which prioritizes the formation of a solid solution of cobalt $\left(\mathrm{Co}_{\mathrm{ss}}\right)$. In fact, a solubility analysis applying the rules of solubility of all metals shows atomic similarities of $0,125 \mathrm{~nm}, 125 \mathrm{~nm}, 0,136 \mathrm{~nm}$ and $0,137 \mathrm{~nm}$ of atomic radius for $\mathrm{Co}-\mathrm{Cr}-\mathrm{Mo}-\mathrm{W}$, respectively [11].

Furthermore, all the solutes have CCC structure, therefore, with similarities between them, which also contributes to the high solubility of Co with these solutes. 


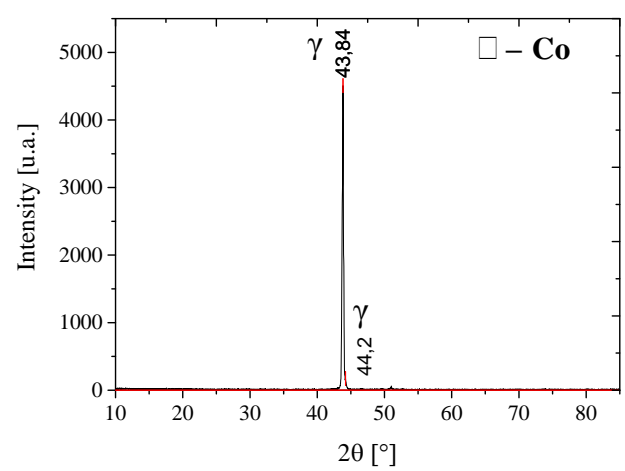

Figure 6: X-ray diffraction of the Co-Cr-Mo-W alloy developed in this work

\subsection{Microhardness Vickers (HV)}

The Table 2 presents the results of the hardness test developed in this study. In this table are included referenced values prioritized by the ASTM F75 and ASTM1537 standards for metal alloys used as materials for dental implants.

Table 2: Mechanical properties of the alloy analyzed.

\begin{tabular}{|c|c|c|c|}
\hline \multirow{5}{*}{$\begin{array}{c}\text { Alloy Co-Cr- } \\
\text { Mo-W }\end{array}$} & \multicolumn{3}{|c|}{ Vickers Hardness } \\
\hline & $100 \mathrm{gF}$ & $500 \mathrm{gF}$ & $1000 \mathrm{gF}$ \\
\hline & 351 & 328 & 304 \\
\hline & \multicolumn{3}{|c|}{ Rockwell Hardness C } \\
\hline & 35 & 33 & 30 \\
\hline \multicolumn{4}{|c|}{ References } \\
\hline ASTM F75 & \multirow{2}{*}{\multicolumn{2}{|c|}{$\begin{array}{c}\text { Rockwell } \\
\text { Hardness C }\end{array}$}} & 5 to 35 \\
\hline ASTM F1537 & & & to 40 \\
\hline
\end{tabular}

The results referring to values of Vickers hardness were converted to the Rockwell $\mathrm{C}$ scale and indicate hardness between $30 \mathrm{HRC}$ to $35 \mathrm{HRC}$, results that meet the ASTM standards.

\section{CONCLUSION}

It was studied a based Co-Cr-Mo-W alloy with chemical composition according to ASTM F75 standards. The many phases present were identified by optical microscopy and scanning electron microscopy. The microstructures agreed upon those published in literature and were well identified by chemical etching.

Through the peaks of the diffractogram we confirmed the cobalt prevalence, where only its peaks are identified. On the basis of the diffractograms it was possible to realize the interplanar spacing calculations, being possible to confirm the formation of solid phase by the other elements, chromium, molybdenum and tungsten, where we conclude that the higher is the solute concentration, the higher is the interplanar spacing.
At last, the alloy attained hardness between 30 $\mathrm{HRC}$ and $35 \mathrm{HRC}$, meeting the standards for dental prosthesis applications.

\section{REFERENCES}

[1]. SOARES, G. A. Biomateriais. Rio de Janeiro: UFRJ, v. 1, 2005. 84 p. Fórum de Biotecnologia e Biomateriais.

[2]. SHI, D. Introduction to Biomaterials. [S.1]: World Scientific, 2006. 123p.

[3]. ANUSAVICE, K.J. Phillips - Materiais Dentários. 11 Edição. Ed. [S.1]: Artmed Editora, 2004. 344 p. ISBN 8536303700.

[4]. BALDISSERA, S. C. "Caracterização microestrutural e resistência à corrosão de ligas Co-Cr-Mo utilizadas em próteses dentárias", Dissertação de Doutorado, Faculdade de Engenharia do Campus de Guaratinguetá, Universidade Estadual Paulista, Guaratinguetá, 2007.

[5]. VOORT, G.F.V. James Hughston M. Wrought Heat-Pesistante Alloys ASM Handbook metallography and Microestructure, vol.9, 1985, p. 207

[6]. BARAN, G.R. The metallurgy of Ni-Cr alloys for fixed prosthodontics. J Prosthet Dent., Philadelphia, v.50, n.5, Nov. 1983, p. 639-650

[7]. KULMBURG, A. et all. The Microstructure of CO-Cr-Mo-(Nb) Dental Alloys Prakt. Metallogr. 38 (2001) 9, p.514-531

[8]. ANAGELINE, E.; ZUCCHI, F. In vitro corrosion of some $\mathrm{Co}-\mathrm{Cr}$ and $\mathrm{Ni}-\mathrm{Cr}$ alloys used for removable partial dentures: influence of heat treatments. Journal of Materials Science: Materials in Medicine, London, v.27, n.35, p.27-35, 1991.

[9]. GARCIA, A. Solidificação: fundamentos e aplicações Campinas, SP, UNICAMP, 2001, $399 \mathrm{p}$

[10]. Mancha H, Carranza E, Escalante JI, Mendoza G, Méndez M, Cepeda F, et al. M23C6 carbide dissolution mechanisms during heat treatment of ASTM F-75 implant alloys. Metall Mater Trans A 2001;32:97984, doi:10.1007/s11661-001-0355-8.

[11]. CALLISTER, WILLIAM D.; Materials Science and Engineering An introduction; $7^{\circ}$ Ed., 975 p.; 2007. 